research findings to change clinical practice is an increasingly recognised phenomenon and is not confined to prenatal screening. ${ }^{1516}$ Part of the answer may lie in the lack of feedback staff receive from their patients. Some women seek help outside the health service, contacting agencies such as Support After Termination for Fetal Abnormality (SATFA), the Down's Syndrome Association, and the Royal College of Obstetricians and Gynaecologists. After Down's syndrome is diagnosed most women opt to terminate their pregnancies. They therefore cease being under the care of antenatal staff, who consequently may remain ignorant of their unmet needs.

What should be done? Detailed specifications for good services exist. ${ }^{17} 18$ They emphasise the importance of training and supporting professional staff to allow them to counsel women appropriately. There is, however, little empirically based work to guide practice in this area. There is a need, for example, to evaluate the effectiveness of different approaches to providing care so as to reduce distress and to maximise adjustment and satisfaction with decisions about continuing or interrupting pregnancies. Are better outcomes achieved by training antenatal clinic staff to counsel or by including a trained counsellor as part of the care team? Only with answers to questions like this can we select the best way of caring for the growing number of couples who will face the pain of a diagnosis of a fetal abnormality.

Purchasers hold one of the keys to improving services. They could stipulate in contracts for prenatal screening services that clinical teams providing the screening are trained to provide information and emotional support at all stages of screening and diagnosis. Clinical audit of prenatal screening programmes needs to include assessment both of women's satisfaction with the service and of psychological outcomes, particularly among those recalled on testing. No matter how good a test is technically, screening of uninformed, unsupported patients by unprepared staff is a recipe for at best confusion and at worst great distress. And it is avoidable.

THERESA M MARTEAU Director

Psychology and Genetics Research Group,

United Medical and Dental Schools of

Guy's and St Thomas's,

London SE1 9RT

1 Working Group on the Screening for Neural Tube Defects. Report. London: Department of Health and Social Security, 1979. (D Black, chairman.)

Royal College of Physicians. Prenatal diagnosis and genetic screening: community and servic implications. London: Royal College of Physicians, 1989.

3 Holland WW. Screening: reasons to be cautious. BMJ 1993;306:1222-3.

4 Marteau TM, Slack J. Psychological implications of prenatal diagnosis for patients and health professionals. In: Brock DJH, Rodeck CH, Ferguson-Smith M, eds. Prenatal diagnosis and screening. London: Churchill Livingstone, 1992:663-73.

5 Statham H, Green J. Serum screening for Down's syndrome: some women's experiences. $B M \mathcal{F}$ 1993;307:174-6.

6 Farrant $W$. Stress after amniocentesis for high serum alpha-fetoprotein concentrations. $B M \mathcal{F}$ $1980 ; 281: 452$.

Griffiths MD, Gough MH. Dilemmas after ultrasonic diagnosis of fetal abnormality. Lancet 1985;i:623-4.

8 Lloyd J, Laurence KM. Sequelae and support after termination of pregnancy for fetal malformation. $B M$ 1 $^{1985 ; 290: 907-9}$.

9 Black RB. A 1 and 6 month follow-up of prenatal diagnosis patients who lost pregnancies. Prenatal Diagnosis 1989;9:795-804.

10 Iles S. The loss of early pregnancy. Bailliere's Clin Obstet Gynaecol 1989;3:769-90.

11 Marteau TM, Cook R, Kidd J, Michie S, Johnston M, Slack J, et al. Psychological effects of false positive results in prenatal screening for fetal abnormality: a prospective study. Prenate Diagnosis 1992;12:205-14.

12 White-van Mourik MAA, Connor JM, Ferguson-Smith MA. The psychosocial sequelae of a second-trimester termination of pregnancy for fetal abnormality. Prenatal Diagnosis 1992;12: 189-204.

13 Marteau TM, Slack J, Kidd J, Shaw RW. Presenting a routine screening test in antenatal care: practice observed. Public Health 1992;106:1311-41.

Whelton JM Sharing the dilemmas: midwives' Professional Nurse 1990:July:514-8.

15 House of Lords Select Committee on Science and Technology. Priorities in medical research. London: HMSO, 1988.

16 Peckham M. Research and development for the National Health Service. Lancet 1991;338:367-71.

17 Drife JO, Donnae D, eds. Antenatal diagnosis of fetal abnormalities. London: Springer-Verlag, 1991.

18 Royal College of Obstetricians and Gynaecologists. Report of the working party on serum screening for Down's syndrome. London: RCOG, 1993.

\title{
No escape: HIV transmission in jail
}

\author{
Prisons need protocols for HIV outbreaks
}

Her Majesty's prison services offer all inmates HIV education and counselling and have a research strategy to establish the prevalence of risk behaviour and of HIV infection among inmates. Some prisons offer condoms to prisoners who are being released and provide drug rehabilitation programmes. ${ }^{1}$ Current measures did not, however, prevent the recent outbreak of hepatitis B and HIV transmissions in a Scottish jail (p 151). ${ }^{2 a}$ The prison services have achieved much in their fight against HIV transmission but there are political and legal barriers to further progress. Urgently needed is a public health protocol that can be implemented when HIV transmission occurs in a jail. This protocol must guarantee prisoners the right to medical confidentiality while ensuring that accurate epidemiological information is collected.

The prison services have worked hard to educate inmates to avoid HIV infection but, unlike other citizens, prisoners are denied condoms and cannot disinfect any needle that they might use. Nearly half of Edinburgh's adult injector inmates had injected during incarceration ${ }^{34}$; one sixth of 16-20 year olds in October 1992 in Polmont, Scotland's largest male young offenders' institution, were injectors, of whom a quarter had injected during their prison terms. ${ }^{5}$ Outside prison, needle exchanges are well established and it is the possession of prohibited injectable substances, not the actual injecting, that breaks the law. A prison sentence, prohibiting access to clean needles for injectors, may become a death sentence. If politicians had the humanity to grant prisoners the same rights to reduce their risk of HIV infection as the rest of the population then prison services could help inmates to stop endangering each other, and they could deliver those rights without risking disorder in the prisons. Practical initiatives are impeded for lack of political will and legal reform.

The prison services' second achievement is to have encouraged officer volunteers to train as HIV counsellors so that confidential, personal HIV testing is available to inmates. Only the Scottish Prison Service has published relevant performance data ${ }^{6}$ Prisoners are unlikely to come forward for testing if they doubt the confidentiality of the results or the medical and social support for HIV infected prisoners. We have reported notably increased uptake of confidential named HIV testing by inmates in temporal association with voluntary anonymous HIV surveillance in prisons. ${ }^{57}$

Prison services in the United Kindom have embraced 
anonymous methodologies, using voluntary saliva samples and linked self completed questionnaires as a means of establishing the prevalence of HIV infection and HIV risk behaviour in prisons and young offenders institutions. The studies, conducted by independent research teams, have shown that inmates are more likely than the outside population to have injected drugs, to have had many female sexual partners, and to have had sex with other men. ${ }^{3-5}$ The clear public health implication of this research is that prisoners have a greater need than the general population for practical means of harm reduction - both condoms and rehabilitation programmes for drug users. HIV education alone is not enough to escape the death sentence of HIV transmission in jail.

When HIV seroconversion occurs in a prison other inmates must be told at the earliest opportunity that this has happened and that the extent of that transmission is not yet known. The confidentiality of the inmate who has seroconverted must be protected. Inmates should be reminded that if they have recently engaged in risk behaviours in prison they should consider having a confidential blood test for HIV and hepatitis B. Confidential counselling facilities from outside the prison should be made available to prisoners. Prisoners must be reminded that if their most recent exposure was within 12 weeks they may continue to test negative for antibodies to HIV despite having been infected-they should therefore repeat the test. Meanwhile, an amnesty should be declared for prisoners to surrender needles; condoms should be made available; and the prison should set up a drug rehabilitation programme. For public health purposes, inmates should be asked to provide voluntary samples of saliva for anonymous HIV and hepatitis B testing and to fill in a linked questionnaire to assess their risk factors. This should be done by an outside research team, and the results reported first to inmates. This surveillance will assist the prison service in advising ex-prisoners and those transferred to other prisons, some of whom may also have been exposed to HIV infection. Such anonymous testing and risk factor elicitation is the best way to minimise volunteer bias.

Prisoners who volunteer know that the information is for specific public health purposes, that the results will be published, and that the exercise is designed to make volunteering attractive by demonstrable anonymity, use of saliva (not blood) samples, and self completion questionnaires. Similar research exercises have been conducted previously, with good cooperation from prisoners. ${ }^{3-5}$ To maximise compliance inmates must be fully and frankly informed about how anonymity is secured.

Against the backdrop of anonymous surveillance (because it promotes requests for personal tests), ${ }^{57}$ there is need to facilitate prisoners' determination of their personal HIV and hepatitis status with maximum confidentiality. This is best met by using outside HIV counsellors and by allowing inmates the opportunity not otherwise available to them of confidential, coded (but unnamed) blood tests so that the inmate, and only he, can access his test result. The result should be duly returned by the same counsellor who first interviewed him. Information given in confidence to HIV counsellors cannot be used for research or public health purposes $^{8}$ without prior ethical clearance, advance notice to, and the permission of, the men concerned. Requesting such permission undermines the confidentiality of the counselling session to follow and hence its value to prisoners. Requesting permission retrospectively-for example, at the anxious time when a HIV test result is returned-is inappropriate because the prisoner cannot retract what has already been confided.

Good epidemiology is essential to inform present planning and future policy. Previous research and the recent seroconversion in a Scottish prison suggest that prisons worldwide provide an environment that predisposes to the transmission of HIV. Understandably, prison authorities will feel more confident to tackle the sensitive and challenging implications of HIV transmission within prisons when scientifically secure data become more widely available. These must quantify the relative risks for HIV transmisison within individual prisons.

Experience suggests that inmates' suspicion of authority can be overcome by frank discussion about the need for public health information to plan the delivery of health care in prisons. The challenge now is to transform data into policy. The tragic experience in Scotland makes this an urgent priority for any national strategy directed towards the public health prevention of further HIV transmission.

MRC Biostatistics Unit,
Institute of Public Health, SHEILA M GORE Senior statistician Cambridge CB2 2SR

Department of Immunology,

A GRAHAM BIRD

Churchill Hospital,

Oxford OX3 7LJ Consultant immunologist

1 Freeman J. HIV tests offered after jail infections. The Glasgow Herald 1993 June 25.

2 Christie B. HIV outbreak investigated in Scottish jail. BMF 1993;307:151

2a Simpson E. STV News 1993 July 10.

3 Bird AG, Gore SM, Joliffe DW, Burns SM. Anonymous HIV surveillance in Saughton Prison, Edinburgh. AIDS 1992;6:725-33

4 Bird AG, Gore SM, Joliffe DW, Burns SM. Second anonymous HIV surveillance in Saughton Prison, Edinburgh: prisoners give a lead to other heterosexuals on being HIV tested. AIDS 1993 (in press).

5 Bird AG, Gore SM, Burns SM, Duggie JG. First voluntary anonymous HIV surveillance with risk factor elicitation in a young offenders' institution: Polmont in Scotland. BMf (in press).

6 Gore SM, Basson J, Bird AG, Goldberg DJ. Uptake of confidential, named HIV testing in Sconish prisons. Lancet 1992,340:907-8.

Gore SM, Joliffe DW, Bird AG. Prisoners' uptake of confidential, named HIV testing. Lancet 1992;339:1491-2.

8 Royal Statistical Society. Code of Conduct: the Public Interest. London: RSS, 1993.

9 UK Health Departments. AIDS-HIV infected health care workers: practical guidance on notifying patients. London: UK Health Departments, 1993

0 Bird AG, Gore SM. Revised guidelines for HIV infected health care workers. BMJ 1993;306: 1013-4. 